\title{
Adolescents Talking about Personal Responsibility
}

\author{
Dr Amanda Mergler and \\ Professor Wendy Patton \\ Queensland University of Technology, Australia
}

\section{Acknowledgements}

We would like to thank the following people for their invaluable assistance with this study. A very big thank you to the high school students who participated in the focus groups, and to the guidance counsellors, year-level coordinators and school principals who assisted with this research.

Keywords: personal responsibility, adolescence, moral development, cognitive development, choices, behaviour, consequences.

\begin{abstract}
The role of personal responsibility in the lives of adolescents remains a largely overlooked area in the psychological and educational fields. The present study used focus groups of 20 white, middle-class adolescents to examine how they understand and integrate the notion of personal responsibility into their lives. Key themes, including awareness of thoughts and feelings, behavioural choices and control, and consideration of consequences were found to be important components of the personal responsibility variable. Interesting gender differences were noted, with females and males identifying different emotions as being within or outside their control, and only females said that concern for the feelings of others was a major factor in decision-making. The key themes served to generate parameters with which to define the personal responsibility variable.
\end{abstract}




\section{Adolescents talking about personal responsibility}

The perceived lack of individual personal responsibility is credited with a growing number of society's ills. Doherty (1998) argued that there is a growing trend in society to refuse accountability and to blame others for one's situation. There is an increase in the number of newspaper articles asking what has happened to personal responsibility, and politicians are increasingly highlighting a need to recapture and interweave a personally responsible agenda into the social fabric. Society is beginning to question why people seem reluctant to take responsibility for their actions (Reeves, 2004).

The belief that people should take personal responsibility has appeared in business, politics, the legal arena, and in health. In these areas, personal responsibility is most commonly understood as accepting accountability for one's action, or lack of action, and the resulting consequence(s) (Doherty, 1998; Evans, 1994; Lupton, 1998; Reeves, 2004; Schulz \& Cheng, 2002; Winston, 2003). If we expect people to be personally responsible, it is imperative that we determine how people understand, learn about and integrate personal responsibility into their lives. One group often considered by the media to be irresponsible is adolescents. To date however, very few researchers in the psychological field have examined how adolescents perceive and enact personal responsibility.

\section{Adolescent cognitive and moral growth}

For many years, the adolescent period, which generally covers the age range 10-18 years (Berzonsky, 2000), has been widely acknowledged as centring on the exploration of the self and one's place in the social world. During adolescence, perhaps more so than at any other time, young people are creating their identity, and discarding values and behaviours that they perceive as incongruent with the picture of themselves they are creating (Dembo \& Eaton, 2000). Essentially, adolescents become inquisitive about who they are (Hacker, 1994). In the search for answers, they move toward a more abstract understanding of themselves, and their selfconcept becomes more developed and better organised (Bacchini \& Magliulo, 2003). Importantly, adolescents begin to judge themselves against the standards and beliefs they themselves subscribe to, and give less emphasis to social comparison (Steinberg \& Morris, 2001). In this way, the adolescent begins to make independent choices and assessments about who they are, who they will be, and how they will act in the world.

This active construction of knowledge and experience occurs throughout life, but it is not until adolescence that complex cognitive development occurs. Piaget (1932) generated a stage-based understanding of cognitive development, with each stage characterised by distinctly different features in the way young people think (Richardson, 1998). It is the development of formal operations that allows adolescents to consider their choices, weigh actions against their consequences, reflect on how their choices and actions are affecting their lives, and consider the viewpoints of other people (Gullota, Adams, \& Markstrom, 1999; Keating, 1980). This developing ability of self-reflection allows adolescents to monitor and select 
their feelings and responses (Hacker, 1994). As such, adolescents have the power to choose how they will feel about, and react to, various situations. Glasser (1998) argued that as adolescents are cognitively capable of sophisticated reasoning, they must be ultimately responsible for the choices they make.

The way adolescents reason about moral dilemmas and situations is the basis of adolescent moral development (Kohlberg \& Hersh, 1977). Kohlberg's (1976) view of morality highlights the active construction of a succession of cognitive structures, each able to resolve conflicts and contradictions produced by previous ways of thinking about moral issues. Adolescence has been marked as a period in which young people become passionately interested in moral questions (Gilligan, 1987). Their developing cognitive sophistication enhances their ability to question the moral domain (Byrnes, 2003). Hacker (1994) contended that the adolescent's ability to think abstractly is directed toward establishing a deeper and more profound understanding of her or his place in the world. Kohlberg (1981) noted that Piaget's (1932) development of formal operations in adolescence encouraged and enabled the advance in moral questioning and reasoning that first appears at that stage.

Kohlberg (1981) believed that moral development moved individuals toward an increased sense of moral autonomy and a more adequate conception of justice. Justice, the primary regard for the value and equality of all human beings and for reciprocity in human relations, is a central tenet in Kohlberg's theory, and was argued to be a basic and universal standard (Singer, 1999). A major challenge to the universality of Kohlberg's principle of justice has come from Gilligan and colleagues (Gilligan, 1977; Gilligan \& Belenky, 1980; Gilligan \& Murphy, 1979). These researchers presented a number of studies that examined the moral choices men and women make in real-life situations, differing from past studies that used male only participants in hypothetical situations. Based on these findings, Gilligan (1982) felt that a single moral perspective, justice, was insufficient to understand women's moral judgements, and introduced the care perspective as an alternative approach to moral decision making.

The care orientation of moral reasoning articulated by Gilligan differed from the justice orientation in several ways. Kohlberg's justice orientation emphasised rights, individual autonomy, equality, and fairness. Gilligan's care orientation, in contrast, emphasised responsibility to others, relationships, sensitivity to social context, and compassion (Moshman, 1999). Interestingly, Gilligan did not dismiss Kohlberg's justice concept, but suggested that both justice and care should inform any model of moral development.

The development that occurs in cognitive and moral reasoning enables adolescents to focus on the thoughts they have, and effect change if their thoughts are not delivering the outcomes they desire. Hacker (1994) contended that active choosing, and accepting responsibility for one's choice, are behaviours that must develop in adolescence. As adolescents mature, they are expected to demonstrate personally responsible behaviour (Hacker, 1994). Entering their final years of schooling, becoming eligible for a driver's licence, and preparing to enter either tertiary education or the workforce, generates an expectation from the community 
that adolescents will begin to demonstrate a greater depth of personal and social awareness.

\section{The present study}

This study used focus groups to explore with adolescents their understanding of personal responsibility, and the way in which they integrate this construct into their lives. Focus groups are a valuable way in which to gain information on the behaviours, attitudes, and opinions of young people, due to their informal nature and flexible format (Berg, 2004).

Examining personal responsibility in adolescents allows us to explore a developmental timeframe centred on growth in the cognitive and moral domains. It allows us to decide whether adolescents are cognitively and morally sophisticated enough to understand personal responsibility and to act accordingly. Further, as adolescents are evolving into independent young adults facing life-changing choices, it is valuable to establish the role personal responsibility may play in this process.

\section{Method}

\section{Participants}

Twenty Year 11 high school students drawn from two public high schools in southeast Queensland, Australia participated in the study $(\mathrm{F}=13, \mathrm{M}=7)$. All participants were aged either 15 or 16 and were white and middle-class. The schools were suburban and based in medium-sized cities.

\section{Focus group interview schedule}

We developed a number of questions pertaining to personal responsibility based on previous reading and related research. The focus group sessions were opened with a scenario deemed relevant to the lives of Year 11 students. As personal responsibility is a concept that is difficult to pin down and may not be easily understood by some adolescents, it was deemed valuable to situate the construct within a familiar situational setting. The scenario described an adolescent returning home after curfew from a party due to their staying late with a friend who they felt may have been in danger. Their parents were angry and the adolescent was grounded.

Questions particular to this scenario were: 'What choices have been made?' 'How do you feel about your parent's reaction and how do you respond?' and 'How do you feel about the outcome (being grounded)?' Further questions which formed part of the focus group discussion included, 'What does personal responsibility mean to you?' 'If you broke personal responsibility down into its key parts, what would they be?' 'Can you think of an example where you really struggled to control your emotions and/or behaviour? What was happening for you at that time?' 'Do you believe you can control your emotions and behaviours?' 'If you feel that someone is holding themselves accountable for their choices and behaviour, what does that mean to you?' 'Do you hold yourself accountable for the choices you make, behaviours you enact, and the outcomes from these?' 'Do you believe it is 
important to take personal responsibility? Why, why not?' 'What in your life do you take personal responsibility for?' 'What do you do that shows you that you are taking personal responsibility for those things?' and 'Where or from whom did you learn about personal responsibility?'

\section{Procedure}

Students were approached during year level assembly and invited to participate. Ten participants were sought from each school and this number was reached through voluntary participation. Students took home a parental consent form that explained the research. This form was signed by a parent and returned by the child before they participated in the focus group. There were four focus groups of four to six students each. The adolescents were encouraged to enter into a conversational dialogue and ask questions. Each focus group lasted 30 to 50 minutes and was audiotaped.

\section{Analyses}

We analysed the interview transcripts using Krueger's (1998) 'content analysis continuum model', which allowed common notions to be grouped together to highlight key themes. Each transcript was systematically analysed to uncover words and concepts that were mentioned within each group and across groups (Krueger, 1998). All focus group questions were listed and the participants' answers were recorded, tallied and grouped. This allowed for the dominant themes to emerge within which personal responsibility could be organised. Each theme was examined alongside the next to delete repetition and ensure all salient aspects of personal responsibility put forward by the adolescents had been captured. As an important component of the focus groups was to find out how adolescents defined and understood personal responsibility, quotes from students were included as illustrative examples of each theme extracted (Fine, Weis, Weseen, \& Wong, 2000).

\section{Results and discussion}

\section{Accepting personal responsibility is internal and about the self}

Adolescents made the point that being personally responsibility was about making their own choices about their behaviour. Most felt that personal responsibility had an internal element, which meant that one decided upon one's own level of responsibility based on one's own choices and behaviour. They felt that the authority for responsibility was one's own and while one could be blamed for certain things, only the individual could truly determine what they were responsible for. When asked how they would define, explain, or how they understood personal responsibility, adolescents responded with comments such as:

- What goes through your mind when you are choosing to look after yourself.

- Making the right decisions for yourself.

- Knowing that whatever you do is your own choice. 


\section{Cognitive awareness}

As personal responsibility requires the engagement of thought processes and decision making capabilities, a certain level of cognitive awareness is necessary. We wanted to examine the level of cognitive awareness these adolescents demonstrated in relation to their thoughts, feelings, behaviours, and potential consequences. Would year 11 students be aware that they were making choices when they experienced emotions and enacted behaviours? Further, would they feel that they were able to control these cognitive processes? Finally, would they cognitively process the potential consequences when deciding on a behaviour?

\section{Thoughts and feelings}

Interestingly, the adolescents were fairly evenly divided between those who felt they were able, were sometimes able, and were unable, to make concrete choices and control their emotional experiences. Comments made by the adolescents ranged from:

I think we can [control our emotions], you can change your thinking.

Maybe [we can control our emotions], though not all the time.

It is hard [to control your emotions] when someone is having a go at you, making you angry.

No [we can't control our emotions]. If it's so big a thing, you have no choice sometimes.

[Emotions] come out whenever they feel like it.

A number of adolescents referred to being unable to control their emotional responses because people had 'made them feel' certain things. The researcher asked one group of five participants if they felt that other people had the power to make them feel certain things. All five adolescents responded strongly that people could definitely make them feel emotions. They stated it would be impossible to not feel anything at all. The researcher then asked the adolescents that if someone else has made them feel angry, who is responsible for the fact that they are angry and how do they respond to that anger? Interestingly, the adolescents responded that the person feeling the anger (themselves) would be responsible for the feeling and how they dealt with the feeling. One adolescent responded:

It's not [my friend's] responsibility if I'm [angry]. It's not her responsibility to keep me calm, it's my responsibility. But whether I can or not is different.

The response of adolescents in this area was somewhat inconsistent. Most adolescents appeared to believe that they either could not, or could only somewhat, control their emotions, and used language that gave their power over their emotional state away to others (such as made me feel). However, after using such language, some would then argue that how they felt was their own responsibility. Perhaps they drew a distinction between how the original feeling came about (she made me angry) and how they dealt with the feeling (but I am choosing to let that anger go).

An interesting gender difference was revealed when discussing the adolescents' ability to control their emotions. The majority of girls felt that they 
could control anger but not sadness, whereas the majority of boys felt that they could control sadness but not anger. Does this gender difference reflect the fact that our emotional control is culturally contained? If boys feel that they can control their experience of sadness and girls feel that they can control their experience of anger, is each gender capable of controlling both emotions, but given a social loophole not to? Perhaps the fact that society tolerates anger in boys and sadness in girls, and these emotions are more often displayed publicly by the appropriate gender, leads adolescents to feel that these emotional experiences are beyond their control.

\section{Behavioural choices and control}

When looking at the data on behavioural choices made, around two thirds of the adolescents felt that they were able to choose, and therefore control, their behavioural responses. These adolescents highlighted that they were aware that they made choices when deciding what behaviours to enact, and acknowledged that the way they behaved was a result of the standards they had set for themselves. Examples of this are:

It's your responsibility how you behave. We're not three-year-olds, we have to use our adult judgement.

It's your choice how you behave, there's always another option.

A small number of students, however, did not feel that they could control their behaviour. These students said that they lashed out as a result of their emotions getting the better of them. One adolescent commented:

I would like to say that I can control my behaviour but I lash out when I'm all stirred up.

This adolescent then went on to say:

There was this boy and I choked him. I don't know what made me do it, I just lost my temper with him.

This response indicates that the adolescent was not aware of what he was thinking and feeling before the attack, and that he was unable to control his undesirable behaviour. While the adolescent did not place the responsibility for his actions externally (by blaming someone else), he appeared to negate his personal responsibility by stating that he did it because he lost his temper and lashed out. In this way he is suggesting that the emotion and the behaviour were not under his control, and therefore he should not be held responsible for the outcome. Students who felt that they could not control their behaviour often cited external influences as the reason. The most common responses from these students were that peer pressure and alcohol consumption meant that they were unable to exert behavioural control. Comments from these students included:

Sometimes people may talk you into [bad behaviour] and you'll do it.

You can't control your behaviour when you are drunk and I usually get drunk after something really bad happens.

This last comment was made by a student who said that he often got drunk to cope with his father's violence and commented that his behaviour while intoxicated 
included hitting people. Another participant in the focus group strongly contested the idea that we are not responsible for our choices when we are intoxicated. This adolescent stated:

You are responsible ... you can choose what you do when you're drunk.

This response suggests an awareness of choices that the first adolescent does not appear to possess.

As expected, those adolescents who feel they are in control of their emotions and behaviour were more willing to take responsibility than those who are not in control. Therefore, the ability to understand cognitions, emotions, and choices is imperative to the willingness of adolescents to take responsibility for their lives. Until adolescents understand and accept that they are making deliberate choices about their feelings and reactions, they will be less likely to accept responsibility for their decisions and their outcomes.

\section{Consideration of consequences}

The majority of adolescents stated that potential consequences largely moderate their behaviour. When asked if they consider the consequences when deciding what to do in a situation, the majority of adolescents replied with always or often. One student noted:

When I get angry with teachers I hold my anger back by thinking of the consequences. If I punched the teacher I would get expelled.

It appears that consideration of the consequences of their behaviour is a fundamental way in which adolescents monitor their behaviour. Adolescents spoke about making the decision to start their assignments earlier after considering the stress, tiredness, and possible drop in academic performance that may occur if they left it until the last minute. This example indicated that they were concerned about the possible consequences to themselves and therefore took the responsible option and began their assignments earlier. It appears essential then, that adolescents are made aware of the consequences of their thoughts, emotions, and behaviours as they make their way through life.

Effects on their parents were seriously considered by adolescents when making decisions. Adolescents appear willing to accept the consequences for their actions when they have caused their parents anguish. The initial scenario, which presented an adolescent being grounded by angry parents because she or he had broken curfew, was regarded as a fair consequence by most adolescents. They argued that they had been aware of the rules and had chosen not to obey them, and this meant that they should be willing to accept the punishment offered (being grounded for a month). The adolescents stated:

[Having our parents angry at us and being grounded] would be a fair enough reaction because we know we are in the wrong and that we didn't follow the rules.

Our parents' reaction is fair because we have broken the rules and should expect punishment.

Our parents' reaction is normal and fair because they are worried about us. 
However, adolescents did talk about the fact that they will make decisions that their parents would not approve of (such as getting drunk at parties). They said that they consider the consequences of alternative actions and choose the one with the least painful outcome. For example, the students remarked that the punishment would be greater if they came home from a party intoxicated as opposed to coming home half an hour past curfew. Armed with this knowledge, the adolescents would get drunk at the party and come home later when they were sober. Thus their thought process focused on how parents would react and how to minimise bad effects on themselves, rather than analysing their behaviour and being responsible.

An interesting fact that came through in the focus groups was that some adolescents who were prepared to accept the parentally enforced consequences in the initial scenario, saying that they were aware of the rules and had decided to break them, were making choices that their parents would not agree with because they were unlikely to get caught doing so. For example, one boy spoke about the fact that he does not go to school before $10.30 \mathrm{a} . \mathrm{m}$. as he has the house to himself in the mornings and can therefore skip school without his parents knowing. This appears to show that he has not internalised responsibility for his own learning and is motivated solely by what his parents may or may not do.

Many adolescents discussed the need to take personal responsibility in order to avoid punishment and negative social consequences, as the following quotes show:

[It is important to take personal responsibility] because if not there'll be consequences that you may not like, so to avoid this you have to follow the rules.

[It is important to take personal responsibility] because if you don't you'll get punished.

If an adolescent's desire to take personal responsibility predominantly comes from a fear of punishment, it stands to reason that an absence of punishment would decrease motivation to be responsible. If parents and schools, for example, do not enforce rules when students behave irresponsibly, students may have little internal motivation to correct their behaviour. Indeed students rated their parents, and the punishments imposed by their parents, as a key way in which they learn about personal responsibility.

\section{How adolescents learn about personal responsibility}

\section{Parents}

The majority of adolescents felt that the bulk of their knowledge of personal responsibility came from their parents. They said that they learnt from their parents by direct instruction ('Your parents do teach you a little bit, like they tell you, "oh that's your responsibility"'), discussion ('My mum has taught me many things and when I hear about what happened in her life it makes me not want to do those things'), and consequences for unacceptable behaviour ('I lied to my mum about where I had stayed and when she found out I got grounded for a week'). 
One student clearly showed how her father had influenced her willingness to take responsibility when talking about a time when she had not taken personal responsibility. She said:

I got suspended [from a private school] for smoking and the deputy tried to blame the other kids and my dad jumped in and said, 'she is $100 \%$ responsible for her own actions and she knows that. It's not their fault'.

She went on to say that her father was right, and that if she had taken responsibility for her behaviour and not smoked at school she would have not have been suspended. She said that her behaviour had resulted in her expulsion from that school when she was in year 8 and how she was now aware that she was now in a public school (which in her eyes was less prestigious) because of her actions. She added:

If I was more responsible I don't think I'd be here ... I would still be in [a private school], but I had to come here.

It appears that her father's direct reference to her not taking responsibility taught her to take responsibility for her behaviour. She appears aware that she made choices of her own accord and is therefore responsible for their outcome.

In contrast, another student spoke about being caught with smokes and his mother's inaction. He commented:

I got caught with them once in my bag, and once when I was selling them to another mate ... and then my mum went through my bag and found them again. She goes, 'have you been smoking?' [I reply] no!

The researcher asked this student if anything happened as a result. If his mother did not like him smoking, and she found that he was smoking, what did she do to enforce her rules? The adolescent said that she threatened to take his money away from him. When asked if this actually happened, and if he accepted this, he replied:

I could [accept the consequence], but I can't let her take my money away. My [mobile] phone is everything and that's where my money goes.

While the adolescent acknowledged that he was not acting responsibly, he was not prepared to accept the consequences. As his mother did not enforce discipline, it appears that this young man is learning that while there may be consequences from our behaviour, we can simply ignore them, seriously undermining his willingness to take responsibility.

\section{Friends}

While most adolescents did mention the influence of their friends as a way in which they learnt about responsibility, they did not offer much detail about how this worked. When encouraged to elaborate, most adolescents had a difficult time coming up with an explanation. It was only female participants (and only those in the all female focus group), who discussed how they had learnt about personal responsibility from their friends. These young women drew attention to the fact that 
they learnt to be responsible through social interactions where they had let a friend down or been let down by a friend, as the following quotes demonstrate:

I put my friend in that position where I left her house and went off for a walk and she was worried, frightened and crying when I got back. That was the position I had put her in and I learnt not to do that to my friends.

I've actually been in that situation before [where a friend will not come home from a party on time] and I actually, I went up to her and I said, 'Look, I'm leaving now. You can either come with me or you don't. You know you're supposed to come home with me so you can either stay and get in trouble by your parents and mine or you can come home now'. And she came home.

Understanding what it feels like when you act irresponsibly and hurt others, or when people act irresponsibly and hurt you, led to an internalisation of behaving responsibly to avoid causing pain to others. Interestingly, only female participants raised personal responsibility in this way. As females are socialised to place greater emphasis on the effect of their behaviour on others, it makes sense that the young women in this study highlighted the influence of their behaviour on others as a major consideration in their choice of behaviour. These findings agree with the argument offered by Gilligan (1977) that women focus on the notion of care when making moral decisions.

\section{Adolescent developmental desires}

Adolescents were asked if they felt that it was important to take responsibility for their lives and if so, why? The majority of students felt that it was very important to take responsibility, and argued that in doing so they would receive greater freedom, increased maturity and live better lives. Adolescent comments included:

We've got to show our parents we are responsible so we can have more freedom.

[Taking personal responsibility] helps you mature.

[Taking personal responsibility] helps you become a better person.

Those who don't take personal responsibility don't come out on top.

Interestingly, these comments reflect what is happening developmentally for adolescents. Adolescence is a time when young people want increased freedom from parental control and punishment (Berzonsky, 2000). They are maturing and wish to be viewed as mature beings. They are beginning to make wider decisions about the direction their lives will take and the opportunities they will pursue (Hacker, 1994). Instinctively, adolescents appear to appreciate that acting responsibly will demonstrate to others that they are maturing and capable of greater freedom. Further, it will assist them to reach their goals and lead successful lives. As one adolescent commented:

We as teenagers expect so much freedom, and we've got to give a little back, to be able to get it. So we've got to show them that we are responsible, so we can have freedom and everything else that goes with it. You've gotta give and take a little. 


\section{Components of personal responsibility}

Listening to the voices of adolescents allows us to define parameters which describe personal responsibility. These focus groups helped us to identify key areas to consider when analysing how adolescents understand and integrate the notion of personal responsibility into their lives. Gilligan's (1987) assertion that young people are passionately interested in moral questions was demonstrated by the study, with participants giving thoughtful, reflective and articulate responses.

The idea that adolescents are actively creating and exploring their identities and place in the world (Berzonsky, 2000) was also supported. Adolescents talked about moving away from parental control and making their own decisions about what was responsible behaviour. They further highlighted their desire to take personal responsibility, as doing so allowed them greater freedom and showed they were maturing. It is a positive sign that adolescents link responsibility with becoming a successful adult. The participants appear to agree with Glasser (1998) that, as they are capable of complex reasoning, they must be responsible for the choices they make.

For most adolescents, and females in particular, being personally responsible meant being aware of how one's actions affected others. Adolescents felt that behaviour that negatively affected their parents was unfair and that being punished was appropriate, as they had 'broken the rules'. This reasoning aligns with Kohlberg's (1981) notion of justice as a central tenet of moral reasoning - the idea that choices should value others and generate reciprocity in human relationships. Additionally, females focused on negative moral decisions as those that caused worry, fear and sadness to family and friends, showing connection to Gilligan's (1982) care orientation of moral reasoning, which focuses on relationships, sensitivity to social context and compassion.

From the findings presented in this paper, we consider that personal responsibility in adolescents has four components. These are: (1) an awareness of, and control over, one's own thoughts and feelings; (2) an awareness of, and control over, behavioural choices; (3) a willingness to hold oneself accountable for one's behaviour and its outcome (consequence); and (4) an awareness of, and concern for, the impact of one's behaviour upon others.

Our study has listened to the voices of adolescents to discover how they understand and integrate personal responsibility in their lives. Future research in this area could seek to reaffirm our findings with an additional sample of adolescents and explore the construct with different cultural groups. Additionally, the views of parents and teachers on the role that personal responsibility may play in the lives of adolescents would further illuminate the construct. Including these groups in discussions could identify the effect that socialisation in the family and the role of formal education has on personal responsibility. This knowledge could serve to inform family and school-based education programs directed at making adolescents more responsible. As the exploration of the personal responsibility variable is in its early stages, this study has enabled the voices of adolescents to be heard to inform our understanding of this important construct. 


\section{References}

Bacchini D \& Magliulo F, 2003, Self-image and perceived self-efficacy during adolescence. Journal of Youth and Adolescence, 32(5), 337-350.

Berg BL, 2004, Qualitative Research Methods for the Social Sciences (5th ed.). Pearson Education, USA.

Berzonsky MD, 2000, Theories of adolescence. In: G Adams (ed) Adolescent development: The essential readings. Blackwell Publishers, Oxford, UK, pp. $11-28$.

Byrnes JP, 2003, Cognitive development during adolescence. In: GR Adams \& MD Berzonsky (eds) Blackwell handbook of adolescence. Blackwell Publishing, Oxford, pp. 227-246.

Dembo MH \& Eaton MJ, 2000, Self-regulation of academic learning in middle-level schools. The Elementary School Journal, 100(5), 473-491.

Doherty B, 1998, Blame society first. Reason, 30(2), 8.

Evans MK, 1994, Accept responsibility. Industry Week, 243(4), 72.

Fine M, Weis L, Weseen S \& Wong L, 2000, For whom? Qualitative research, representations, and social responsibilities. In: NK Denzin \& YS Lincoln (eds) Handbook of qualitative research (2nd ed). Sage Publications, California, pp. 107-132.

Gilligan C, 1977, In a different voice: Women's conception of self and morality. Harvard Educational Review, 47(4), 481-517.

Gilligan C, 1982, In a Different Voice: Psychological Theory and Women's Development. Harvard University Press, Cambridge, MA.

Gilligan C, 1987, Adolescent development reconsidered. New Directions for Child Development, 37(Fall), 63-92.

Gilligan C \& Belenky M, 1980, A naturalistic study of abortion decision. In: R Selman \& R Yando (eds) Clinical-developmental psychology. Jossey-Bass, San Francisco, pp. 69-90.

Gilligan C \& Murphy J, 1979, Development from adolescence to adulthood: The philosopher and the dilemma of the fact. In: D Kuhn (ed) Intellectual development beyond childhood. Jossey-Bass, San Francisco, pp. 85-99.

Glasser W, 1998, Choice Theory: A New Psychology of Personal Freedom. Harper Collins, New York. 
Gullota TP, Adams GR \& Markstrom CA, 1999, The Adolescent Experience (4th ed.). Academic Press, San Diego.

Hacker DJ, 1994, An existential view of adolescence. Journal of Early Adolescence, 14(3), 300-327.

Keating DP, 1980, Thinking processes in adolescence. In: J. Adelson (ed) Handbook of adolescent psychology. Wiley, New York, pp. 211-246.

Kohlberg L, 1976, Moral stages and moralization: The cognitive developmental approach. In: T Lickona (ed) Moral development and behaviour: Theory, research, and social issues. Holt, Rinehart \& Winston, New York, pp. 31-53.

Kohlberg L, 1981, Essays on Moral Development: The Philosophy of Moral Development. Moral Stages and the Idea of Justice (Vol. 1). Harper and Row, San Francisco.

Kohlberg L \& Hersh RH, 1977, Moral development: A review of the theory. Theory Into Practice, 16(2), 53-59.

Krueger RA, 1998, The Focus Group Kit. Sage Publications, California.

Lupton D, 1998, A postmodern public health. Australian and New Zealand Journal of Public Health, 22(1), 3.

Moshman D, 1999, Adolescent Psychological Development: Personality, Morality, and Identity. Lawrence Erlbaum Associates, New Jersey.

Piaget J, 1932, The Moral Judgement of the Child. Harcourt, Brace, New York.

Reeves R, 2004, Why everyone is talking about responsibility. New Statesman, 17, 33-35.

Richardson K, 1998, Models of Cognitive Development. Psychology Press, East Sussex.

Schulz AKD \& Cheng MM, 2002, Persistence in capital budgeting reinvestment decisions - personal responsibility antecedent and information asymmetry moderator: A note. Accounting and Finance, 42(1), 73.

Singer MS, 1999, The role of concern for others and moral intensity in adolescents' ethicality judgments. The Journal of Genetic Psychology, 160(2), 155-166.

Steinberg L \& Morris AS, 2001, Adolescent development. Annual Review of Psychology, 52, 83-110.

Winston P, 2003, Laws can't protect you from yourself. Business Insurance, 37(38), 6. 